\title{
APOLIPOPROTEIN AI-CIII GENE POLYMORPHISMS IN JAPANESE MYOCARDIAL INFARCTION SURVIVORS
}

\author{
Juichi Satoh, ${ }^{1}$ Naoko HatTori, ${ }^{1}$ Mieko ONUKI, ${ }^{1}$ \\ Kimiko Yamakawa, ${ }^{1}$ Hideomi Fujiwara, ${ }^{2}$ Hiroshi Amamiya, ${ }^{2}$ \\ Hideo Nagaoka, ${ }^{2}$ Tohru SaKuma, ${ }^{3}$ Yasuko Yamanouchi, ${ }^{1}$ \\ Takaaki OKafuJI, ${ }^{1}$ Yukio IWamura,${ }^{1}$ Shigeru TsuChIYA, ${ }^{4}$ \\ Hisayuki Fukutomi, ${ }^{5}$ Toshiaki Ohsuga, ${ }^{5}$ and Hideo Hamaguchi ${ }^{1}$ \\ ${ }^{1}$ Institute of Basic Medical Sciences, ${ }^{4}$ Institute of Community Medicine, and ${ }^{5}$ Institute \\ of Clinical Medicine, University of Tsukuba, Niihari-gun, Ibaraki 305, Japan \\ ${ }^{2}$ Tsuchiura-kyodo Hospital, Tsuchiura, Ibaraki 300, Japan \\ ${ }^{3}$ Tsukuba Medical Center, Niihari-gun, Ibaraki 305, Japan
}

\begin{abstract}
Summary To search for a linkage marker for the putative deleterious atherogenic gene in the apo AI-CIII-AIV gene complex in Japanese, apo CIII Sst-I genotypes and apo AI Msp-I genotypes were investigated in 69 Japanese myocardial infarction survivors, using genomic hybridization analysis, and compared with the genotypes in 82 healthy subjects. Unlike the association of the $S 2$ and $M 2$ alleles with myocardial infarction found in Caucasians, there were no differences in both the frequencies of the $S 2$ and $M 2$ alleles between Japanese myocardial infarction survivors and healthy subjects. The individual with the haplotype $51-M 2$, however, was significantly increased in myocardial infarction survivors compared with the one in healthy subjects $\left(24 \%\right.$ versus $11 \% ; \chi^{2}=4.90$, d.f. $=1, \mathrm{p}<$ $0.05)$. The data suggest that the haplotype $S 1-M 2$ may be a linkage marker for the putative atherogenic gene or may show regional differences in the frequency in Japanese.
\end{abstract}

\section{INTRODUCTION}

Apolipoprotein AI and CIII (apo AI and CIII) play an important role in the metabolism of plasma lipoproteins and lipids (Herbert et al., 1983). The human apo AI and apo CIII genes are tightly linked and form a gene complex together

Received November 18, 1986; Accepted December 23, 1986

Offprint request to: Hideo Hamaguchi, Institute of Basic Medical Sciences, University of Tsukuba, Niihari-gun, Ibaraki 305, Japan. 
with the apo AIV gene on the long arm of the chromosome 11 (Karathanasis, 1985). A mutation of the apo AI gene is associated with low plasma HDL and premature atherosclerosis (Karathanasis et al., 1983a, 1983b). In addition, restriction fragment length polymorphisms related to the apo $\mathrm{AI}$ and apo $\mathrm{CIII}$ genes have been reported to be associated with coronary atherosclerosis and familial hypoalphalipoproteinemia in Caucasians (Ferns et al., 1985; Rees et al., 1985; Sidoli et al., 1985; Ferns and Galton, 1986; Ordovas et al., 1986; Buraczynska et al., 1986; Deeb et al., 1986; Acton et al., 1986). An apo AI-CII gene polymorphism associated with coronary atherosclerosis may be a linkage marker for an atherogenic gene in the apo AI-CIIIAIV gene complex. Such a linkage marker is likely to vary among the races.

In the previous study, we revealed that the haplotypes identified by the apo CIII $S s t-I$ and apo AI $M s p$-I polymorphisms are useful genetic markers for Japanese (Onuki et al., 1986). In the present study, the haplotypes identified by the apo CIII Sst-I and apo AI $M s p$-I polymorphisms were investigated in Japanese myocardial infarction survivors, as an attempt to find a linkage marker for the putative atherogenic gene in the apo AI-CIII-AIV gene complex in Japanese.

\section{MATERIALS AND METHODS}

Blood was collected from 69 Japanese myocardial infarction survivors without diabetes mellitus (59 males, 10 females) attending the cardiac clinics at Tsuchiurakyodo Hospital and Tsukuba Medical Center, Ibaraki-ken. Diagnosis was confirmed by clinical history, typical electrocardiographic changes and enzyme examination. The mean $( \pm S D)$ age of the myocardial infarction survivors was $59 \pm 10$.

DNA was isolated from whole blood cells essentially according to the method of Kunkel et al. (1977). The apo CIII Sst-I genotypes and apo AI Msp-I genotypes were analyzed by Southern blotting using ${ }^{32}$ P-labeled human apo AI clone composing $2.2 \mathrm{~kb}$ Pst-I fragment of an apo AI genomic clone as described previously (Southern, 1975; Kessling et al., 1985; Onuki et al., 1986).

Association analysis between myocardial infarction and the haplotype identified by the apo AI-CIII $S s t$-I and $M s p$-I polymorphisms was performed in $2 \times 2$ tabies by chi-square statistics. In the association analysis, the data on 82 unrelated healthy members of the university staffs and students (age range 20-62, mean age $30 \pm 12$ ) were used as the control; the data was described in detail previously (Onuki et al., 1986).

\section{RESULTS}

Figure 1 shows simplified restriction site maps for the Sst-I and Msp-I polymorphisms in the apo AI-CIII genes. Table 1 presents the distribution and allele frequencies of the apo CIII Sst-I genotypes and apo AI Msp-I genotypes in 69 myocardial infarction survivors and 82 unrelated healthy subjects. Both the frequencies of the $S 2$ and $M 2$ alleles were high in myocardial infarction survivors and healthy 

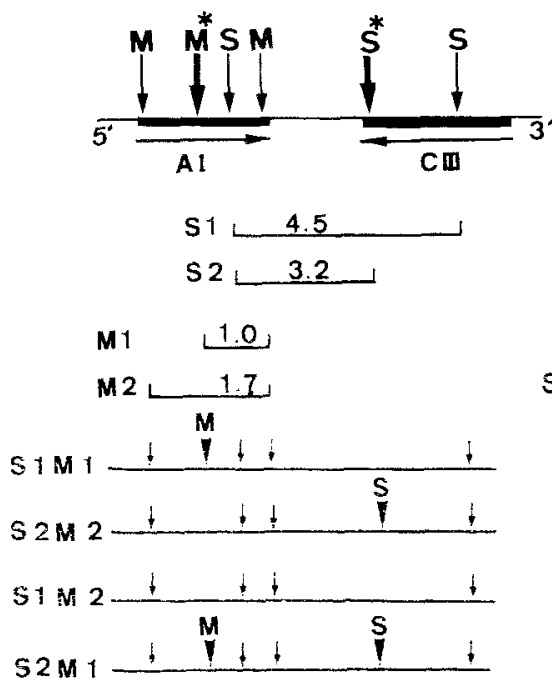

$\begin{array}{cc}\begin{array}{c}\text { Healthy } \\ \text { Subjects } \\ N=82\end{array} & \begin{array}{c}\text { Survivors } \\ N=69\end{array} \\ 0.604 & 0.558 \\ 0.341 & 0.319 \\ 0.055 & 0.123 \\ 0 ? & 0 ?\end{array}$

Fig. 1. Simplified restriction site maps for the $S s t-I$ and $M s p-I$ polymorphisms in the apo AI-CIII genes. $S^{*}$ and $M^{*}$ represent the polymorphic sites for the enzyme Sst-I and $M s p-I$, respectively. Two alleles for each polymorphic site and the four possible haplotypes are shown. Arrowheads on the haplotype indicate the presence of the site for the enzyme $S s t-\mathrm{I}(\mathrm{S})$ or $M s p-\mathrm{I}(\mathrm{M})$. Frequencies of each haplotype in myocardial infarction (MI) survivors and healthy subjects are also described.

Table 1. Distribution and allele frequencies of the apo CIII Sst-I genotypes and apo AI Msp-I genotypes in myocardial infarction (MI) survivors and healthy subjects.

\begin{tabular}{|c|c|c|c|c|c|c|}
\hline \multirow[b]{2}{*}{ Apo CIII Sst-I } & \multirow[t]{2}{*}{$\mathrm{N}$} & \multicolumn{3}{|c|}{ Genotypes $(\%)$} & \multicolumn{2}{|c|}{ Allele } \\
\hline & & $S I S I$ & $S 1 S 2$ & $S 2 S 2$ & $S I$ & $S 2$ \\
\hline MI survivors & 69 & $20(40.6)$ & $38(55.1)$ & $3(4.3)$ & 0.68 & 0.32 \\
\hline Healthy subjects & 82 & $37(45.1)$ & $34(41.5)$ & 11 (13.4) & 0.66 & 0.34 \\
\hline Apo AI $M s p-I$ & & $M 1 M I$ & $M 1 M 2$ & $M 2 M 2$ & $M I$ & $M 2$ \\
\hline MI survivors & 69 & $20(30.0)$ & $37(53.6)$ & $12(17.4)$ & 0.56 & 0.44 \\
\hline Healthy subjects & 82 & $32(39.0)$ & $35(42.7)$ & $15(18.3)$ & 0.60 & 0.40 \\
\hline
\end{tabular}

subjects, and no significant differences in the frequencies of the alleles were observed between the two groups.

In the previous study we clearly demonstrated that the alleles identified by the apo CIII Sst-I and apo AI $M s p$-I polymorphisms are in linkage disequilibrium (Onuki et al., 1986). As observed in the previous study, none of 69 subjects examined in this study had the genotypes, S1S2MIMI, S2S2M1MI, and S2S2M1M2. Since the haplotype $S 2-M I$ is considered to be absent, or, if present, very rare and 
Table 2. Distribution of combined haplotype in myocardial infarction (MI) survivors and healthy subjects.

\begin{tabular}{|c|c|c|c|c|c|}
\hline \multirow{2}{*}{ Combined haplotype } & \multicolumn{2}{|c|}{ MI survivors } & \multicolumn{3}{|c|}{ Healthy subjects } \\
\hline & $\mathrm{N}$ & $(\%)$ & $N$ & & $(\%)$ \\
\hline$S 1 M 1 / S I M 1$ & 20 & & 32 & & \\
\hline$S 1 M 1 / S 2 M 2$ & 29 & $52(75.4)^{2}$ & 30 & 73 & $(89.0)$ \\
\hline$S 2 M 2 / S 2 M 2$ & 3 & & 11 & & \\
\hline$S I M I / S I M 2$ & 8 & & 5 & & \\
\hline$S 2 M 2 / S 1 M 2$ & 9 & $17(24.6)^{2}$ & 4 & 9 & $(11.0)$ \\
\hline Total & 69 & $(100)$ & 82 & & $(100)$ \\
\hline
\end{tabular}

${ }^{2} \chi^{2}=4.90$, d.f. $=1, \mathrm{p}<0.05$, when compared with healthy subjects.

negligible in Japanese, the combination of the haplotypes identified by these polymorphisms is easily determined for each individual when the genotypes of the polymorphisms are known. Table 2 shows the distribution of the combined haplotypes in myocardial infarction survivors and healthy subjects. The frequency of the individuals with the haplotype $S 1-M 2$ (that is genotypes SISIMIM2, SIS2M2M2) is significantly increased in myocardial infarction survivors compared with healthy subjects $(24.6 \%$ versus $11.0 \%, \mathrm{p}<0.05)$. The frequency of each haplotype in myocardial infarction survivors and healthy subjects is shown in Fig. 1; the frequencies of the haplotype S1-M2 are 0.123 in myocardial infarction survivors and 0.055 in healthy subjects, and the difference is also significant $\left(\chi^{2}=4.30\right.$, d.f. $\left.=1, p<0.05\right)$.

\section{DISCUSSION}

The $S 2$ and $M 2$ alleles, especially the $S 2$ allele, have been reported to be relatively uncommon and associated with coronary atherosclerosis in some local Caucasians (Ferns et al., 1985; Rees et al., 1985; Ferns and Galton, 1986; Deeb et al., 1986; Acton et al., 1986). In the case of Japanese, however, our data indicate that both the $S 2$ and $M 2$ alleles are common and not associated with coronary atherosclerosis. The apo CIII $S$ st-I polymorphism arises from a C-G transversion in the $3^{\prime}$-non-coding region of the apo CIII gene (Karathanasis et al., 1983a). The apo AI $M s p$-I polymorphism arises from the presence or absence of a $M s p$-I site in the third intron of the apo AI gene (Seilhamer et al., 1984). Therefore it is considered that the $S 2$ and $M 2$ alleles may represent a linkage marker for an atherogenic gene at least in some local Caucasians but not in Japanese.

The haplotypes identified by the apo CIII Sst-I and apo AI Msp-I polymorphisms are useful genetic markers for the analysis of apo AI-CIII-AIV gene complex in Japanese (Onuki et al., 1986). The results of the present study suggest that the haplotype $S 1-M 2$ may be a linkage marker for the putative atherogenic gene in 
Japanese. Our data seem to be consistent with the finding reported by Rees et al. (1986) that the haplotype $S 1-M 2$ is associated with hypertriglyceridemia in Japanese (Rees et al., 1986). However, since the difference in the frequency of the haplotype $S 1-M 2$ between myocardial infarction survivors and healthy subjects may reflect regional differences, it is required to perform further case-control studies to confirm the results of the present study.

Acknowledgments We are grateful to Dr. S.E. Humpries, St. Mary's Hospital Medical School, London for giving us a human apo AI clone. We thank Miss Mariko Sugawara, University of Tsukuba for the preparation of the manuscript.

This study was supported by a Scientific Research Grant from the Ministry of Education, Science and Culture, No. 61571088, and a Research Grant for Intractable Diseases from the Ministry of Health and Welfare, Japan.

\section{REFERENCES}

Acton, R., Vanichanan, C., Olson, G., Chandler, G., Barger, B., Go, R., Roseman, J., and Copeland, R. 1986. Immunogenetic and AI-CIII polymorphisms are risk factors for early onset coronary heart disease. Abstracts of the 7th International Congress of Human Genetics 750, West Berlin.

Buraczynska, M., Hanzlik, J., and Grzywa, M. 1986. ApoA-I related DNA polymorphism in humans with coronary heart disease. Hum. Genet. 74, 165-167.

Deeb, S., Motulsky, A., Failor, A., Walker, D., Brunzell, J., and Albers, J. 1986. Molecular genetics of apolipoproteins and coronary heart disease. Proceedings of the 7 th International Congress of Human Genetics, West Berlin, p. 747

Ferns, G.A.A., Stocks, J., Ritche, C., and Galton, D.J. 1985. Genetic polymorphisms of apolipoprotein C-III and insulin in survivors of myocardial infarction. Lancet II: 300-303.

Ferns, G.A.A. and Galton, D.J. 1986. Haplotypes of the human apoprotein AI-CIII-AIV gene cluster in coronary atherosclerosis. Hum. Genet. 73: 245-249.

Herbert, P.N., Assman, G., Gotto, A.M., and Fredrickson, D.S. 1983. Familial lipoprotein deficiency: Abetalipoproteinemia, hypobetalipoproteinemia, and Tangier disease. In The Metabolic Basis of Inherited Disease, Stunbury, J.B., Wyngaarden, J.B., Fredrickson, D.S., Goldstein, J.L., and Brown, M.S., eds., McGraw-Hill, New York, pp. 589-621.

Karathanasis, S.K., Norum, R.A., Zannis, V.I., and Breslow, J.L. 1983a. An inherited polymorphism in the human apolipoprotein A-I gene locus related to the development of atherosclerosis. Nature 301: 718-720.

Karathanasis, S.K., Zannis, V.I., and Breslow, J.L. 1983b. A DNA insertion in the apolipoprotein A-I gene of patients with premature atherosclerosis. Nature 305: 823-825.

Karathanasis, S.K. 1985. Apolipoprotein multigene family: Tandem organization of human apolipoprotein AI, CIII, and AIV genes. Proc. Natl. Acad. Sci. U.S.A. 82: 6374-6378.

Kessling, A.M., Horsthemke, B., and Humphries, S.E. 1985. A study of DNA polymorphism around AI gene in hyperlipidaemia and normal individuals. Clin. Genet. 28: 296-306.

Kunkell, L.M., Smith, K.D., Bother, S.H., Borgaonkar, D.S., Wachtel, S.S., Miller, O.J., Breg, W.R., Jones, H.W., and Rary, J.M. 1977. Analysis of human Y-chromosome-specific reiterated DNA in chromosome variants. Proc. Natl. Acad. Sci. U.S.A. 74; 1245-1249.

Onuki, M., Iwamura, Y., Humphries, S.E., Satoh, J., Hattori, N., Yamakawa, K., Yamanouchi, Y, Okafuji, T., and Hamaguchi, H. 1986. Apolipoprotein AI-CIII gene polymorphisms in a Japanese population. Jpn. J. Human Genet. $31: 337-343$.

Ordovas, J.M., Schaefer, E.J., Salem, D., Ward, R.H., Glueck, C.J., Vergani, C., Wilson, P.W.F., and Karathanasis, S.K. 1986. Apolipoprotein A-I gene polymorphism associated with pre- 
mature coronary artery disease and familial hypoalphalipoproteinemia. $\quad$ N. Engl. J. Med. 314: 671-677.

Rees, A., Stocks, J., Williams, L.G., Caplin, J.L., Jowett, N.I., Camm, A.T., and Galton, D.J. 1985. DNA polymorphisms in the apolipoprotein C-III and insulin genes and atherosclerosis. Atherosclerosis 58: 269-275.

Rees, A., Stocks, J., Paul, H., Ohuchi, Y., and Galton, D.J. 1986. Haplotypes identified by DNA polymorphisms at the apolipoprotein A-I and C-III and hypertriglyceridaemia: A study in a Japanese population. Hum. Genet. 72: 168-171.

Seilhamer, J.J., Protter, A.A., Frossard, P., and Levy-Wilson, B. 1984. Isolation and DNA sequence of full-length CDNA and of the entire gene for human apolipoprotein AI: Discovery of a new genetic polymorphism in the apo AI gene. DNA 3: 309-317.

Sidori, A., Giudici, G., Soria, M., and Vergani, C. 1985. Restriction-fragment-length polymorphisms in the A-I-C-III gene complex occurring in a family with hypoalphalipoproteinemia. Atherosclerosis 62: 81-87.

Southern, E.M. 1975. Detection of specific sequences among DNA fragments separated by gel electrophoresis. J. Mol. Biol. 98: 503-517. 